\title{
Comunicação \\ Preparados homeopáticos e adubação verde no controle de Cyperus rotundus L.
}

\author{
Karina de Almeida $^{1 *}$ e Francisco Luiz Araújo Câmara ${ }^{2}$
}

\begin{abstract}
RESUMO
Na busca por métodos de manejo com menor impacto ao ambiente e que se enquadrem nos sistemas orgânicos de produção, este trabalho teve o objetivo de avaliar preparados homeopáticos de plantas de tiririca e o adubo verde mucuna-preta (Stilozobium aterrimum Piper \& Tracy) no controle da tiririca. O experimento foi desenvolvido em vasos, em casa de vegetação, na Fazenda Experimental Lageado, FCA-UNESP-Botucatu, no período de abril/maio de 2008. O delineamento experimental utilizado foi inteiramente casualizado, com três repetições, sendo os tratamentos constituídos por extrato aquoso da mucuna-preta, palhada de mucuna-preta em cobertura de solo e incorporada, preparados homeopáticos das plantas de tiririca, e a testemunha. O extrato aquoso da mucuna-preta e os preparados homeopáticos proporcionaram redução no crescimento da parte aérea e acúmulo de massas de matéria fresca e seca da tiririca. A massa de matéria fresca da parte aérea da mucuna-preta estimulou o crescimento da tiririca, tanto em cobertura como incorporada ao solo.
\end{abstract}

Palavras-chave: plantas invasoras, nosódio, Stilozobium aterrimum Piper \& Tracy.

\section{ABSTRACT}

\section{Homeopathic preparations and green manure to control Cyperus rotundus L.}

In the search for natural herbicides for the management of the Cyperus rotundus L. in crops this work evaluated alternative methods to control weed, aiming at sustainability. The experiment was carried out in pots, in a greenhouse at the Experimental Station Lageado, FCA-UNESP-Botucatu, from april to may 2008. The experimental design was entirely randomized, with three repetitions, and treatments consisted of aqueous extract of Stilozobium aterrimum Piper \& Tracy, residue of the green manure on the soil surface and incorporated into soil, homeopathic preparations and control treatment with no applications. The aqueous extract of green manure and homeophathic preparation provided both reduction in the development of $C$. rotundus. The fresh weight of the aerial part of S.aterrimun stimulated the growth of the weed both as cover and incorporated into the soil.

Key words: invasive plants, nosode, Stylozobium aterrimun Piper \& Tracy.

Recebido para publicação em 05/10/2011 e aprovado em 04/06/2012

'Engenheira-Agrônoma, Doutora. Pós-doutoranda da Empresa de Pesquisa Agropecuária do Estado de Minas Gerais. Rua Visconde do Rio Preto, s/n, Vila São Paulo, 36303-360, São João Del Rei, Minas Gerais, Brasil. kkalmeida@yahoo.com.br (*autora correspondente)

${ }^{2}$ Engenheiro-Agrônomo, Doutor. Departamento de Horticultura, Faculdade de Ciências Agronômicas, Universidade Estadual Paulista (UNESP), Avenida José Barbosa de Barros, 1780, Bairro Lageado, 36303-360, Botucatu, São Paulo, Brasil. chicocamara@fca.unesp.br 


\section{INTRODUÇÃO}

As plantas espontâneas causam graves problemas aos ambientes agrícolas, competem diretamente com os cultivos, reduzindo a produtividade e a qualidade do produto, sendo também hospedeiras de pragas e doenças de plantas cultivadas.

A tiririca (Cyperus rotundus L.) é uma das plantas espontâneas mais disseminadas em todo o mundo. Nativa da Índia, considerada de difícil manejo, por ser agressiva e de ampla adaptabilidade a ambientes agrícolas diversos, provoca reduções quantitativas e qualitativas na produção mundial das principais espécies de valor econômico. Possui características bastante peculiares, apresenta eficiente sistema vegetativo de reprodução por tubérculos. Em condições ambientais favoráveis (alta temperatura e elevada intensidade luminosa), o seu estabelecimento é rápido, pelo intenso crescimento vegetativo. Por apresentar rota metabólica $\mathrm{C}_{4}$, a tiririca é bastante eficiente na assimilação do $\mathrm{CO}_{2}$ atmosférico e, consequentemente, na sua conversão a carboidrato (Silva et al., 2003). Vários estudos vêm sendo realizados com o propósito de complementar os métodos tradicionais de manejo, minimizando os impactos ambientais causados pelo uso abusivo de herbicidas.

A atenção dos pesquisadores tem-se voltado para a busca de alternativas sustentáveis ao uso de herbicidas, visto que a expansão da produção agrícola sob sistema orgânico no Brasil é crescente. Dentre os métodos alternativos, destaca-se a utilização de espécies de plantas que liberam substâncias prejudiciais às outras plantas, fenômeno conhecido como alelopatia, reduzindo ou até mesmo inibindo totalmente o desenvolvimento das plantas espontâneas. A atividade dos aleloquímicos tem sido usada como alternativa ao uso de herbicidas, nematicidas e inseticidas (Norsworythy \& Meehan, 2005).

O efeito da cobertura morta no controle da comunidade de plantas espontâneas vem sendo atribuído à liberação de compostos alelopáticos e a efeitos físicos, que podem estar relacionados com a filtragem da luz, alterando a quantidade e a qualidade do comprimento das ondas luminosas e a manutenção da temperatura, com menores oscilações. A mucuna-preta (Stilozobium aterrimum) e o feijão-de-porco (Canavalia ensiformis DC) são plantas usadas como adubos verdes, que vêm sendo estudadas no tocante aos seus efeitos alelopáticos, visando ao manejo de plantas espontâneas (Balbino-Junior, 2004, Fontanetti, 2007).

O manejo de plantas espontâneas, utilizando a homeopatia, também torna-se uma alternativa, já que os preparados homeopáticos têm o potencial de agir nos agroecossistemas como um todo, possibilitando a produção de alimentos saudáveis em um sistema equilibrado. A
Homeopatia é considerada uma ciência que pode ser aplicada a todos os seres vivos, sejam humanos, animais domésticos ou silvestres, sejam vegetais ou micro-organismos (Rossi, et al., 2004). No Brasil, os preparados homeopáticos foram considerados insumos agrícolas pelo Ministério da Agricultura e do Abastecimento, em maio de 1999 (Brasil, 1999).

De acordo com a teoria homeopática, a doença equivale a um desequilíbrio dinâmico, que pode ter sua correção auxiliada pela utilização de medicamentos previamente experimentados, aplicados em doses mínimas (Rossi et al., 2004). A homeopatia fundamenta-se em quatro princípios: semelhança, doses diluídas e dinamizadas, utilização de um preparado por vez e experimentação em indivíduos sadios. Os preparados homeopáticos são feitos a partir de substâncias naturais provenientes dos reinos animal, mineral e vegetal ou de tecidos doentes (Casali et al., 2006; Castro, 2002). Segundo Rossi et al. (2004), os bioterápicos, ou nosódios (preparações homeopáticas feitas com a matéria-prima originária do próprio organismo) são preparados segundo a farmacopeia homeopática brasileira, com o objetivo de induzir a sua resistência nas plantas.

Neste trabalho, buscou-se estudar os métodos alternativos para o manejo da tiririca (C. rotundus), com cobertura morta, extrato aquoso de mucuna-preta e preparados homeopáticos de plantas de tiririca.

\section{MATERIAL E MÉTODOS}

O experimento foi desenvolvido em casa de vegetação, na Fazenda Experimental Lageado - FCA, UNESPBotucatu, no período de abril a maio de 2008. O delineamento experimental foi inteiramente casualizado, com sete tratamentos e três repetições, sendo a testemunha a ausência de tratamento.

Cada parcela foi constituída por um vaso plástico com capacidade para $5 \mathrm{~L}$ de substrato (subsolo). Em cada vaso, foram plantados, na mesma profundidade, 15 tubérculos sadios da tiririca, previamente selecionados de acordo com o peso, variando entre 25 e 30 g (Azania et al., 2006). Os vasos foram irrigados com água deionizada, até atingir a capacidade de campo, posteriormente, foram pesados e, sempre que seus pesos fossem inferiores aos aferidos na capacidade de campo, foram novamente irrigados.

Os tratamentos foram: preparados homeopáticos $\mathrm{T} 1=$ nosódio da planta inteira de tiririca $(\mathrm{CH} 16 \mathrm{PI}), \mathrm{T} 2$ = nosódio da parte aérea da tiririca (CH16PA), T3 = extrato aquoso da parte aérea da mucuna-preta (EMP) a 5\% e T4= extrato aquoso da parte aérea da mucuna-preta (EMP) a 10\%, T5 = palhada de mucuna-preta (400g matéria fresca/vaso MPC) mantida em cobertura, T6 = palhada de mucunapreta (400g matéria fresca/vaso - MPI) incorporada ao solo 
e T7= testemunha sem tratamento. As aplicações dos tratamentos homeopáticos (T1 e T2) e dos extratos aquosos (T3 e T4) foram realizadas duas vezes por semana, no período de um mês, sendo aplicados $100 \mathrm{~mL}$ dos extratos e dos preparados homeopáticos por vaso. Nos tratamentos T5 e T6, a palhada da mucuna-preta foi colocada nos vasos, em cobertura e incorporada, cinco dias antes do plantio dos tubérculos.

Na confecção dos extratos aquosos, utilizaram-se folhas frescas de mucuna-preta, colhidas no estádio de floração, picadas e imersas em água deionizada, numa concentração em peso/volume de 10\% de massa de matéria seca, à temperatura ambiente, permanecendo em repouso por 2 horas. Posteriormente, foi realizada a filtragem do extrato, com uma peneira de malha fina, e acondicionada em frascos até o momento de sua aplicação. Também foi realizada a diluição do extrato para obtenção do tratamento a 5 \% (Carvalho, 1996). As aplicações dos extratos a 5\% e 10\% foram realizadas diretamente no solo utilizando-se $100 \mathrm{~mL}$ por vaso.

Nos preparados homeopáticos, utilizou-se a escala centesimal hahnemanniana (CH). A tintura mãe (TM) (solução precursora dos preparados homeopáticos) foi confeccionada a partir de plantas inteiras da tiririca (T1) e apenas da parte aérea (T2). Foram coletadas 5 plantas no campo, ao acaso, para cada tintura; foram lavadas e picadas, posteriormente, colocadas em álcool 70\%, maceradas e deixadas em repouso por um período de 15 dias.

As soluções foram filtradas e acondicionadas em frascos âmbar. A partir da tintura mãe (TM) da tiririca (T1 e T2), faz-se o CH1, colocando-se 5 gotas da TM em 20 mL de álcool 70\%. Fez-se, a seguir, a sucussão, ou seja, bateu-se, no mesmo ritmo, 100 vezes. Assim ficou pronto o CH1 para cada tratamento. Repetiu-se o procedimento, a partir do CH1, até chegar ao CH16. As aplicações do CH16 foram realizadas diretamente no solo utilizando-se $100 \mathrm{~mL}$ dos preparados homeopáticos por vaso (Resende, 2003).

As avaliações de massa de matéria fresca e de massa de matéria seca da parte aérea e dos tubérculos, comprimento da parte aérea, número final de plantas e de tubérculos produzidos foram realizadas 45 dias após o plantio.

O comprimento da parte aérea das plantas de $C$. rotundus foi determinado, considerando-se o número total de plantas em cada parcela (vaso); a parte aérea foi medida com o auxílio de uma régua graduada, do solo até o ápice das folhas. Após a avaliação do comprimento da parte aérea das plantas, elas foram lavadas e, posteriormente, pesadas em balança de precisão, para se determinar a massa de matéria fresca total. Posteriormente, com tesoura de poda, os tubérculos foram separados e pesados para determinação da massa de matéria fresca. Em seguida, armazenou-se o material em sacos de papel, os quais foram levados para estufa com circulação forçada de ar, a $65^{\circ} \mathrm{C}$, até atingir peso constante, para determinação da massa de matéria seca.

O número final de plantas foi determinado pela contagem de plantas que emergiram. Para determinação do número total de tubérculos produzidos, foi peneirado o substrato de cada vaso e, posteriormente, realizada a contagem para cada tratamento.

Realizou-se a análise de variância e, para comparação entre as médias, utilizou-se o teste de Scott-Knott, a 5\% de probabilidade, utilizando-se o software Sisvar.

\section{RESULTADOS E DISCUSSÃO}

O desenvolvimento da parte aérea foi comprometido com a aplicação dos extratos de mucuna-preta e dos preparados homeopáticos.

Observou-se diferença significativa entre os tratamentos para todas as variáveis avaliadas. Para a massa de matéria fresca total apenas os tratamentos com palha de mucuna-preta em cobertura e incorporada ao solo, não diferiram da testemunha. Houve redução na produção de massas de matéria fresca tanto da parte aérea como dos tubérculos da tiririca, nos tratamentos que receberam extrato aquoso de mucuna-preta e receberam as aplicações dos preparados homeopáticos, bem como na massa de matéria seca da parte aérea, quando comparados com a testemunha (Tabela 1). Resultado semelhante foi obtido, no trabalho de Carvalho et al.(2002), com redução na produção de massas de matéria fresca e seca da parte aérea da tiririca, com a aplicação de extrato aquoso a $12 \%$.

Os menores valores de produção de massas de matéria fresca e seca total das plantas de C. rotundus foram obtidos pela aplicação do extrato aquoso a $10 \%$ e pelo preparado homeopático da parte aérea da tiririca (CH16PA), com redução de 36\% e 24\% na massa de matéria fresca, 24 e $18 \%$ na massa de matéria seca total, respectivamente, quando comparados com as da testemunha, (Tabela 1). Esses resultados não coincidem com os mencionados por Rossi et al. (2007), os quais não encontraram variações significativas na massa de matéria seca da parte aérea da tiririca, utilizando os preparados homeopáticos nas dinamizações CH3, CH6, CH9, CH12, CH15 e CH18.

Nota-se que não houve diferença significativa entre as aplicações dos extratos de mucuna-preta e dos preparados homeopáticos, na produção de massas de matéria fresca e seca da parte aérea e dos tubérculos da tiririca. O mesmo foi observado para as concentrações dos extratos (10 e 5\%) e para as dinamizações dos preparados homeopáticos (CH16PA e CH16PI - Tabela 1).

A palhada de mucuna-preta, incorporada e sobre o solo, exerceu influencia positiva no desenvolvimento da parte aérea e dos tubérculos da tiririca. Observa-se, pelos dados da Tabela 1 , que para o tratamento com a mucuna- 
preta em cobertura houve maior produção de massa de matéria seca da parte aérea e de matérias fresca e seca de tubérculos. Esse incremento na produção resultou em maior produção total de massa de matéria seca da tiririca. A quantidade insuficiente de massa de matéria fresca (2,8 $\mathrm{t} \mathrm{ha}^{-1}$ ) da mucuna-preta colocada sobre o solo, pode justificar o fato de não ter havido efeito negativo da mucuna sobre o desenvolvimento da parte aérea tiririca, já que o esperado efeito mecânico (barreira física) ficou comprometido, mas não justifica o efeito benéfico observado.

Por outro lado, a mucuna-preta incorporada ao solo exerceu maior influencia sobre a produção de massa da matéria seca dos tubérculos da tiririca, evidenciando o efeito positivo desse tratamento no desenvolvimento dessa espécie. A maior produção de massa de matéria seca de tubérculos refletiu em maior produção total de massa de matéria seca. Esse fato deve-se provavelmente ao aumento de matéria orgânica ao solo, que favoreceu a retenção de umidade, contribuindo para maior retenção e absorção de água e nutrientes pelos tubérculos da tiririca (Tabela 1).
Com exceção do tratamento com palhada de mucunapreta em cobertura, os demais tratamentos favoreceram a produção de tubérculos de tiririca (Figura 1).

Segundo Silveira et al. (2010), o extrato aquoso da parte aérea da mucuna-preta não proporcionou redução do crescimento nem estabilização na multiplicação dos tubérculos, apresentando assim efeito alelopático benéfico em tubérculos da tiririca. Deste modo, é necessário cuidado na recomendação de aplicação desses extratos e preparados homeopáticos, em áreas de produção comercial, pois poderão promover maior infestação de tiririca na área de produção.

O contrário foi encontrado no trabalho de Carvalho et al., (2002), quando o extrato aquoso da parte aérea da mucuna-preta proporcionou redução no crescimento, estabilização na multiplicação de tubérculos $(0,0 \%)$ e menor índice de velocidade de emergência da tiririca, que os da testemunha com água deionizada. Ocorreram variações, na multiplicação, de 3,2 a 4,3 vezes o número inicial de plantas da tiririca, no período avaliado, apresentando,

Tabela 1. Massa de matéria fresca total (MFT), massa de matéria seca total (MST), massa de matéria fresca da parte aérea (MFPa), massa de matéria seca da parte aérea (MSPa), massa de matéria fresca do tubérculo (MFTb), massa de matéria seca do tubérculo de tiririca (MSTb), cultivados em vasos sob diferentes tratamentos de controle

\begin{tabular}{lcccccc}
\hline Tratamentos & MFT & MST & MFPa & MSPa & MFTb & MSTb \\
\cline { 2 - 7 } & \multicolumn{7}{c}{ (g) } \\
\hline T1 - CH16PI & $81,13^{1} \mathrm{~b}$ & $15,88 \mathrm{~b}$ & $29,38 \mathrm{~b}$ & $5,90 \mathrm{c}$ & $24,69 \mathrm{c}$ & $9,59 \mathrm{~b}$ \\
T2 - CH16PA & $67,90 \mathrm{~b}$ & $15,49 \mathrm{~b}$ & $31,82 \mathrm{~b}$ & $6,11 \mathrm{c}$ & $25,01 \mathrm{c}$ & $8,17 \mathrm{~b}$ \\
T3 - EMP a 5\% & $80,01 \mathrm{~b}$ & $15,58 \mathrm{~b}$ & $28,72 \mathrm{~b}$ & $5,59 \mathrm{c}$ & $28,63 \mathrm{c}$ & $9,62 \mathrm{~b}$ \\
T4 - EMP a 10\% & $67,28 \mathrm{~b}$ & $14,33 \mathrm{~b}$ & $32,51 \mathrm{~b}$ & $6,18 \mathrm{c}$ & $23,58 \mathrm{c}$ & $8,17 \mathrm{~b}$ \\
T5 - MPC & $135,79 \mathrm{a}$ & $21,30 \mathrm{a}$ & $65,76 \mathrm{a}$ & $12,19 \mathrm{a}$ & $49,81 \mathrm{a}$ & $13,09 \mathrm{a}$ \\
T6 - MPI & $102,88 \mathrm{a}$ & $25,29 \mathrm{a}$ & $46,10 \mathrm{a}$ & $8,99 \mathrm{~b}$ & $34,37 \mathrm{~b}$ & $12,30 \mathrm{a}$ \\
T 7-Testemunha & $106,68 \mathrm{a}$ & $18,89 \mathrm{~b}$ & $54,10 \mathrm{a}$ & $8,70 \mathrm{~b}$ & $39,11 \mathrm{~b}$ & $10,19 \mathrm{~b}$ \\
\hline CV (\%) & 19,09 & 16,46 & 25,61 & 20,52 & 16,11 & 15,37 \\
\hline
\end{tabular}

${ }^{1}$ Médias seguidas da mesma letra, na coluna, não diferem significativamente a 5 \% de probabilidade pelo teste de Skott-Knott.

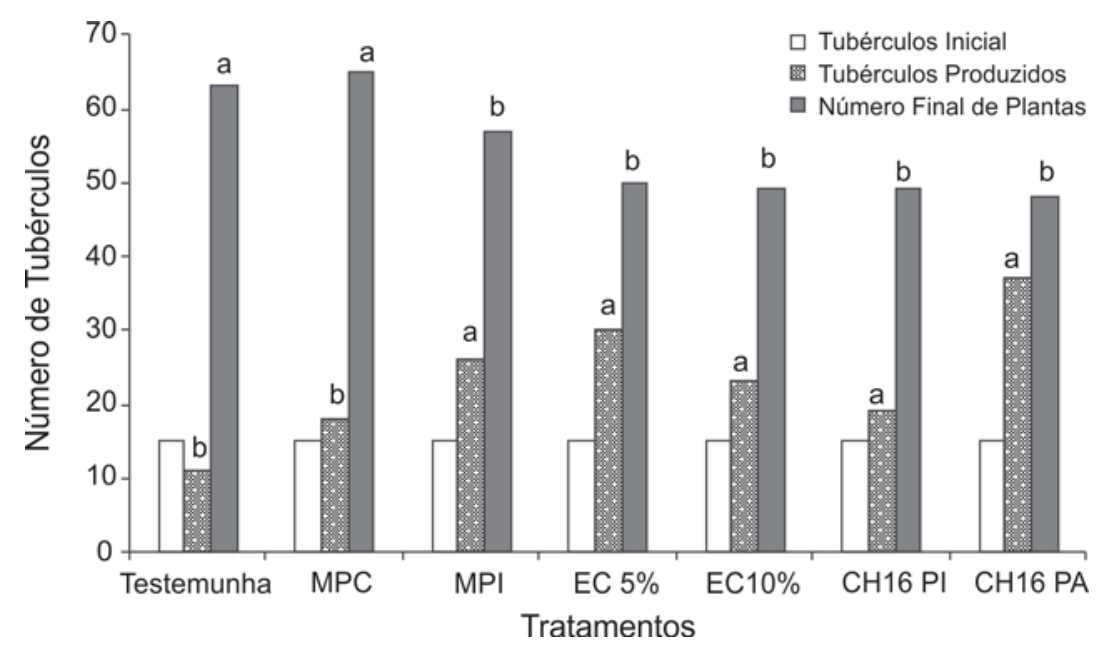

Figura 1. Número inicial de tubérculos, número de plantas no final do experimento e número de tubérculos produzidos durante a condução de experimento de cultivo de tiririca em vasos, sob diferentes tratamentos de controle. Letras sobre as barras comparam os tratamentos pelo teste de Scott-Knott a 5\% de probabilidade. 
provavelmente, efeito alelopático benéfico aos tubérculos. Resultados semelhantes foram encontrados por Fontanetti (2007), que não observou efeito do cultivo de mucuna-preta, no manejo da tiririca. A não redução do número de tubérculos nos tratamentos que envolveram a camada de palha também foi observado por Silva et al., (2003) e Azania et al., (2006), os quais não constataram redução do número de tubérculos em tratamentos envolvendo camada de palha de $16 \mathrm{t} \mathrm{ha}^{-1}$ (massa de matéria seca).

Mais trabalhos, utilizando os preparados homeopáticos, devem ser realizados a fim de elucidar os resultados obtidos neste trabalho.

\section{CONCLUSÕES}

O extrato aquoso da parte aérea da mucuna-preta, nas concentrações de 5 e 10\%, e os preparados homeopáticos CH16PA e CH16PI proporcionaram redução no acúmulo de massa de matéria fresca da parte aérea, de tubérculos e total, bem como da produção de massa de matéria seca da parte aérea da tiririca.

Não obstante o efeito na redução do acúmulo de matérias fresca e seca, os extratos aquosos de mucuna-preta e os preparados homeopáticos CH16PA e CH16PI favoreceram a produção de tubérculos de tiririca.

\section{REFERÊNCIAS}

Azania CAM; Azania AAPM; Pavani MCMD; Alves PLCA (2006) Desenvolvimento da tiririca (Cyperus rotundus), influenciado pela presença e ausência de palha de cana-de-açúcar e herbicida. Planta Daninha, 24:29-35.

Balbino-Junior AA (2004) Manejo das plantas daninhas pela alelopatia. Agropecuária Catarinense, 17:61-64.

Brasil (1999) Instrução Normativa n.7. Normas para produção de produtos orgânicos vegetais e animais. Diário Oficial Republica Federativa do Brasil. Brasília, 11-14.

Carvalho GJ (1996) Análise da potencialidade de autoalelopatia de restos culturais da colheita da cana-de-açucar. Tese de Doutorado, Universidade Federal de Lavras, Lavras, 72p.

Carvalho GJ, Fontanetti A \& Cançado CT (2002) Potencial alelopatico do feijão-de-porco (Canvalia ensiformis) e da mucuna-preta (Stilozobium aterrimum) no controle da tiririca (Cyperus rotundus L.). Ciência e Agrotecnologia, 26:647-651.

Castro DM (2002) Preparações homeopáticas em plantas de cenoura, beterraba, capim-limão e chambá. Tese de Doutorado. Universidade Federal de Viçosa, Viçosa, 240p.

Casali, VWD, Castro, DM, Andrade, FM.C. (2006) Homeopatia: bases e princípios. Viçosa, UFV/ DTF, 149p.

Fontanetti A (2007) Efeito alelopatico de adubos verdes no controle da tiririca (Cyperus rotundus L.). Revista Brasileira de Agroecologia, 2:1365-1368.

Norsworythy, JK \& Meehan JT (2005) Use of isothiocynates for suppression of Palmer amaranth (Amaranthus palmeri) pitted morningglory (Ipomaea lacunose) an yellow nut sedge (Cyperus rotundus). Weed Sci, 53:884-890.
Resende JM (2003) Cartilha de Homeopatia. Instruções práticas geradas por agricultores sobre o uso de homeopatia no meio rural. $1^{\circ}$ Ed. FUNARBE - Fundação Arthur Bernardes UFV, Viçosa, UFV, DFT, CCA, 35p.

Rossi F, Arevalo RA, Ambrosano EJ, Guirado, N.; Ambrosano GMB, Mendes PCD, Mota B, von Atzigen EMM, Menuzzo MM \& Varella AS (2007) Aplicação de preparados homeopáticos no controle da tiririca em área agroecológica. Revista Brasileira de Agroecologia, 2:870-873.

Rossi F, Ambrosano EJ, Melo PCD \& Bréfere FAT (2004) Emprego da homeopatia no controle de doença de plantas. Summa Phytopathologica. 30:156-158.

Silveira HRO, Ferraz EO, Matos CC, Alvarenga IAC, Guilherme EO, Tuffi Santos LD \& Martins ER (2010) Alelopatia e Homeopatia no manejo da tiririca (Cyperus rotundus). Planta Daninha, 2:499-506.

Silva JR, Costa NV \& Martins D (2003) Efeito da palhada de cultivares de cana-de-açúcar na emergência de Cyperus rotundus. Planta Daninha, 21:375-380. 